\title{
THE IMPLEMENTATION OF PROBLEM-BASED LEARNING IN UKRAINIAN HIGHER EDUCATIONAL INSTITUTIONS
}

\author{
Natalia Dmitrenko \\ Vinnytsia State Pedagogical University named after M. Kotsiubynskyi, Vinnytsia, Ukraine \\ nataliadmitrenko0302@gmail.com
}

\begin{abstract}
The article deals with the problem-based learning (PBL) that combines theoretical knowledge and practice in the educational process. PBL is an effective learning method through which the students become responsible and initiative. PBL main goals, principles and steps of implementation are observed in the article. PBL is a constructive, self-directed, collaborative and contextual process and has the potential to prepare students more effectively for future learning and profession. The main objectives of PBL are described in the article: constructing an extensive and flexible knowledge base; developing effective problem-solving abilities; becoming effective collaborators; being motivated to learn, work and research. It is cleared up that PBL focuses on practical learning where students solve real life badly structured problems. It is shown that the educational process is organized around the interdisciplinary problems and it can help students to learn integrally. The participants of problem-based learning process have to plan, monitor and evaluate the learning process actively, interpret prior knowledge and experience and after their self-study and mutual interaction within the group, they are able to construct and reconstruct their knowledge networks. The author states that implementation of PBL in the educational process gives students a sense of ownership over their learning and empowers participants with valuable skills that motivate students to learn and ability to achieve good results. The main ways of implementation of PBL in Ukrainian higher educational institutions and some recommendations are given in the article.
\end{abstract}

Keywords: problem-based learning (PBL); principles of PBL; components of PBL; a tutor; self-study, a tutorial session.

Introduction. Problem-based learning (PBL) is a learner-centered approach introduced by Medical faculty at McMaster University in Canada, almost 50 years ago. Its origin comes from information processing theory, which suggests that learning is more effective when learners are motivated to restructure their previous knowledge based on additional information from a realistic context and by reflecting about recently acquired knowledge. Currently, it's largely employed in medical education worldwide, but also in other fields. This methodology considers the content of the curriculum, the way of learning is processed and empowers the student on learning process ("learning how to learn").

This article provides the review of research on PBL and suggests the ways how to implement PBL in Ukrainian higher educational institutions.

There is no consensus on a definition of PBL. The reason is that several variations of PBL have been implemented and studied. Schmidt (1995) made an attempt at providing a general characterization of PBL: "A collection of carefully constructed and engaging "problems" is presented to small groups of students. These problems usually consist of a description of a set of observable phenomena, situations, or events. The task of the group is to discuss these problems and elaborate on tentative explanations for the phenomena in terms of some underlying process, principle, or mechanisms" (Schmidt, 1995, p. 247).

Problem-based learning is a learning approach that seeks to create a link between theoretical knowledge and practice (Cockrell \& Caplow, 2000). PBL is based on the concepts of Lev Vygotskyi about Social Development Theory, which considers learning as a social construction of knowledge. Due to this origin, PBL recognizes nothing can be learned in totality and learning needs to be shared among transdisciplinary groups (Missimer \& Connell, 2012). It is essential to have collaborative groups in learning contexts to explore, analyze and solve the problems presented (Cockrell \& Caplow, 2000).

PBL main goals are:

1) to develop group learning environments;

2) to help students to learn and understand curriculum contents;

3) to help students to acquire problem-solving skills, to be used in their future practice;

4) to improve communication and professional interaction (Sefton \& Frommer, 2013). 
Five components can be considered as the minimum standard set of necessary and sufficient characteristics that should be present in PBL:

1. Ill-structured problems are presented as unresolved so that students will generate not just multiple thoughts about the cause of the problem, but multiple thoughts on how to solve it (Barrows, 2002).

2. A student-centered approach provides the students with the opportunity to determine what they need to learn: to derive the key issues of the problems they face, define their knowledge gaps, and pursue and acquire the missing knowledge (Barrows, 2002; Hmelo-Silver \& Barrows, 2006).

3. Teachers act as facilitators or tutors in the learning process.

4. Problems are selected from professional or "real world" (Barrows, 2002). The problems are inherently cross-disciplinary and require students to investigate multiple subjects (Barrows, 1996) in order to generate a workable solution.

5. PBL is typically undertaken in a small group setting (Barrows, 2002; Hmelo-Silver \& Barrows, 2006). While groups of five to nine students were used in the original McMaster model for PBL (Barrows, 1996), these later definitions allow for the possibility of PBL without small group work. Thus, the cases of large group PBL were investigated by Barrows with favorable results (Barrows, Myers, Williams \& Moticka, 1986).

Problem-based learning as a method of instruction stands firm within the rationalist tradition and is strongly influenced by cognitive psychology. Its roots can be traced to Dewey's plea for the fostering of independent learning and who stressed the importance of learning in response to and in interaction with real-life events, and also to Bruner's notion of intrinsic motivation as an internal force that drives the person (Schmidt, 1993).

Theoreticians and researchers have proposed a variety of learning principles that are implemented in PBL:

1. The prior knowledge people have regarding a subject is the most important determinant of the nature and amount of new information that can be processed. The availability of relevant prior knowledge is a necessary, yet not sufficient, condition for understanding and remembering new information. Prior knowledge also needs to be activated by cues in the context of which the information is being studied.

2. Knowledge is structured. The way in which it is structured in memory makes it more or less accessible for use.

3. Storing information in memory and retrieving it can be greatly improved when, during learning, elaboration of the material takes place.

4. The ability to activate knowledge in the long-term memory and to make it available for use depends on contextual cues.

5. High learning motivation prolongs the amount of study time (or processing time) and, hence, improves achievement (Clayton, 1996).

These principles are considered to be basic to many forms of human learning, comprehension and problem-solving and are the core of PBL.

There are several educational approaches, which are based on similar principles. They include:

- project-based learning;

- case-based learning;

- competency-based learning;

- content-based learning;

- team-based learning;

- flipped classroom learning;

- task-based learning.

Comparing to all other existing methods based on the direct instruction, PBL positions itself as a method involving a heuristic search of a solution through engaging in team discussions, facilitated rather than led or dominated by the teacher.

While in other learning contexts, PBL is the tool for translating theoretical knowledge into practical decisions within a certain professional domain such as engineering, economics or science. 
What makes problem-based learning unique is its core focus on learning through solving real, open-ended problems to which there are no fixed solutions (Ertmer, Lehman, Park, Cramer, \& Grove, 2003).

Interest in learning has led to several new theories and related research about the underlying principles in the few past decades (Ormrod, 2006). It has also been shown that the four main strategies of PBL are collaborative, contextual, constructive and self-directed learning (Dolmans, De Grave, Wolfhagen, \& Van der Vleuten, 2005). These strategies create an active and meaningful learning environment. Together they foster the cognitive, motivational and social goals related to learning. Literature reveals that in PBL curricula students are more interested and motivated about their learning (Dolmans \& Schmidt, 2006), have better interpersonal skills, better competencies in problem solving, self-directed learning (Schmidt, Vermeulen, \& Van der Molen, 2006) and are more satisfied with the learning situation (Albanese \& Mitchell, 1993).

The PBL approach is characterized by working in small groups on a presented scenario (e.g. problem or case), a teacher who facilitates the process by guiding the students and sufficient time for self-directed learning (Hmelo-Silver, 2004). In theory, this approach enables the students to become more effective collaborators, develop self-directed learning and problem-solving skills, construct an extensive flexible knowledge which goes beyond the learning of facts and raises the intrinsic motivation (Dmitrenko, 2016).

The main steps of a tutorial session are:

1. First, a problem is presented to the students.

2. Students discuss the problem in a small group PBL tutorial. They clarify the facts of the case, define what the problem is, brainstorm the ideas based on the prior knowledge, identify what they need to learn (learning issues), reason through the problem, and specify an action plan for working on the problem.

3. Students are also motivated to an independent study out of the tutorial guidance. This can include libraries, databases, tweb resources, people and observations.

4. Students come back to PBL tutorial(s) for sharing information, peer teaching and working together on the problem.

5. Students present their solution to the problem.

6. Students review what they have learnt from working on the problem. All who participated in the process engage in self, peer and tutor review of the PBL process and reflections on each person's contribution to that process.

Tutorial groups typically consist of 6 to 10 students who meet for 2 to 3 hours per session, usually twice a week (Schmidt et al., 2007). These meetings are guided by a tutor and, in addition, two students in the group assume the roles of chair and scribe. In addition to tutorial meetings, lectures can be part of the curriculum, but their occurrence is intended to be limited (Schmidt et al., 2009) and not compulsory. They are typically comprehensive, rather than transmissive.

Each tutorial group is supported by an academic staff member, called a "tutor" who is meant to facilitate the learning process of the group (Schmidt \& Moust 1998: 5-11; Moust \& Nuy 1987), by asking provocative questions, providing feedback to the chair/secretary or the overall learning process of the group. At no point in time the tutor should lecture the group, but in the case of problems, she/he should support the group in identifying what went wrong and what could be improved to get to a more successful learning process in the next assignment. However, as many colleagues often highlight, it is also extremely important, especially when tutoring PBL-inexperienced students, that the tutor is able to react to potentially distracting group dynamics, and stops the group in case they are "going off the track" (Maurer \& Neuhold, 2012).

A balance is needed from the tutor's part, sometimes more guidance will be needed compared to other times. Students new to PBL will benefit from having a more structured curriculum or more directive tutors. However, students that are used to PBL will benefit from more freedom in their learning path. The tutor should be able to adapt to the level of each student group and also be willing to receive feedback and reflect on how he/she is doing (Walsh, 2005).

The traditional roles of the teacher and students change, and the focus of the methodology becomes student centred rather than teacher centred. In a situation where a student is not the object 
but the subject of education, the role of a tutor can be compared with the conductor of the orchestra. As a conductor, a tutor guides the activities of each student so that the result has obtained from the jointly coordinated work of the whole group.

The main function of the tutor is to organize the whole group to decide this problem. This involves:

- formulation of the problem (task);

- diagnosis of the level of knowledge of group members;

- clarity of the methodical installation;

- creating a positive mental attitude of students;

- the correct and creative selection of methods, forms and methods of instruction;

- monitoring and summarizing of the results.

Assessment in PBL can be done by tutors, peers, or oneself. Tutors can observe the skills and the knowledge that learners use. Learners can reflect on their own work and that of their peers, how well the team works, how they feel about their work and progress, and what skills and knowledge they are gaining. Reflecting on work, checking progress, and identifying areas of strength and weakness are part of the learning process.

One part of the PBL process is regular feedback (called formative feedback) to all group members. It should be done at the end of each tutorial not in the form of marks but as statements and commentaries. Regular evaluation should not be interpreted as an assessment of the tutors' or students' performances, but rather as a means for checking whether this approach is meeting the students' needs and is fitting well within the program. Without this feedback, the problems in the group work may pile up and turn into a really distressing situation. The summative student evaluation (marks, credits) can take different aspects into account. For instance, the criteria can be knowledge application, critical thinking, self-directed study and collaboration, for professionalism and attitude during the discussion.

Problem-based curriculum demands a high standard regarding the problems used as starting points for learning. The purpose of problems is not only to integrate disciplines or subjects, but also to achieve the pedagogical core process of producing learning and competence. The critical point to a successful approach is the selection of ill-structured problems (often interdisciplinary) and a tutor who guides the learning process and conducts at the conclusion a thorough debriefing of the learning experience (Dmitrenko, 2016).

There is some evidence that graduates from PBL schools are better prepared in terms of general competencies than their colleagues from non-PBL schools. Busari et al.(1997) showed that graduates from a PBL school felt better prepared in psychosocial and interpersonal skills. Antepohl et al. (2003) reported that graduates from a PBL curriculum felt well prepared for professional practice in the pre-registration period and specialty training, especially in terms of skills for communicating with people, co-operation with other professionals and the development of critical thinking and a scientific attitude. Schmidt and Van der Molen (2006) showed that alumni of a PBL medical school considered themselves to have been better prepared than their colleagues who had been trained in traditional curriculum with respect to the skills needed to collaborate with others, solve problems, run meetings and work independently. There was no difference in general academic knowledge and the ability to write reports or papers. According to Koh and colleagues (2008) graduates of problem-based learning curriculum had better diagnostic and communication skills; had a greater appreciation for the cultural aspects of care as well as legal and ethical issues; demonstrated greater responsibility, and were better able to cope with uncertainty. However, other competencies, such as planning and organizing work, are in need of more explicit attention in undergraduate training (Norman, 2008). Schlett et al (2010) showed that among medical graduates in Germany, PBL demonstrated benefits with regard to competencies which were highly required in the job of physicians. Similar results showing better performance of PBL vs traditional methods were showed by the study of Imanieh et al (2014). Meo (2013) showed that students in the PBL group obtained significantly higher knowledge and skill scores in the respiratory physiology course compared with students in the traditional (LBL) style of medical schools. In other health students, like pharmacists, Galvao et al (2014) showed that knowledge was improved by the PBL method. It may be concluded 
that problem-based learning method leads to a significant increase in learning and recalling output compared to the traditional method.

Despite its increasing use and popularity, the PBL approach remains controversial. The main reason for this controversy is that in spite of being the subject of extensive research, some aspects and influences of PBL remain unclear. For Ukrainian educators, it is interesting to know how to implement interdisciplinary approach (on which PBL is based) within Ukrainian context with its strict division between academic disciplines and university departments.

Problem-Based Learning is a very broad concept that can be applied to a specific course or guide the set-up of the whole curriculum. Preconditions and challenges can be identified on three different levels: on the level of curriculum planning and structural preconditions; on the level of course planning (course assignment and other form of preparation); and last, on the level of implementation (role of tutors, students' performance and group dynamics) (Maurer \& Neuhold, 2012).

Setting-up a university programme based fully on PBL is resource-intense: splitting the student cohort into groups of 6-10 puts considerable constraints on scheduling and organisation. It has to be considered that for this kind of teaching an appropriate number of smaller rooms with the necessary equipment is needed (i.e. whiteboard, eventually beamer and computer) that also allow the group to face each other (i.e. to sit in a circle). As self-study is a central element of students to learn in a PBL environment, the importance of the library also increased considerably: students are supposed to have access to various kinds of literature, and students also spend a vast amount of their time in the library reading and preparing during their self-study. Additionally, PBL is staff-intensive for the faculty, as each tutorial group has to be accompanied by a tutor.

One of the major problems anticipated with the implementation of PBL in Ukrainian learning process is the disparity between the nature of PBL and Ukrainian traditional educational settings. Firstly, their goals are different. While PBL aspires to lifelong skills, traditional educational settings covet curriculum coverage and excellence in high-stake examinations (Hmelo-Silver, 2004; Savery, 2006). Thus, PBL's student-centred approach and a strong focus on process skills may not be considered a superior approach to the tried-and-tested methods of teaching. Hence, there is the possibility of reverting to the didactic, drill-and-practice methods that have seemingly proven their worth over the years. Another source of complication comes from the disparity between the rigid university structure in Ukraine and the more fluid and multidisciplinary nature of PBL. The highly structured classroom organization and the compartmentalized subjects in the Ukraine university curriculum present a hurdle in accommodating the flexibility in time and subject organization needed for the implementation of PBL.

Unfortunately, interdisciplinary approaches are not supported well by formal education institutions that divide and identify problems in terms of strict disciplinary perspectives. It turns out that the transition to PBL in an existing institute with its own traditions on teaching and learning has serious challenges. It makes a difference whether PBL is concentrated in isolated projects or it is considered a leading principle throughout the curriculum. As a result, there is a multitude of more or less differentiated PBL formats, mixing characteristics of case-based and project organized PBL and integrating more or less elements from the traditional curriculum. institutions:

One may follow the next advice in shifting to PBL curriculum in Ukrainian higher educational

1. Look at the curriculum as a whole, including all curriculum elements.

2. Think of the coherence between the curriculum and the organization culture.

3. Employ a range of strategies for change, adapting to the situation.

4. Create a general view of the total change process.

5. Motivate staff and students.

6. Develop visions for long-term goals without compromising short-term goals.

7. Plan the development of teaching competences.

8. Raise funds.

9. Participate in network activities.

10. Establish a staff development unit responsible for recurring energizers.

11. Provide proof of the development of students' learning outcome. 
12. Provide proof of the development of faculty's capacity.

The main concern of Ukrainian teachers is about the ability of integrated blocks to cover the relative subjects to the extent which is demanded by the final objectives of the degree programme. PBL courses designers state that "The members of the block planning group are responsible for ensuring maximum coverage by the block period for which they are responsible. This means that careful selection of the subjects to be offered is of the essence" (Graff, 2013).

Conclusions. Thus, PBL is an outstanding model that meets the needs of our modern society and encourages successful life-long learning.

Problem-based learning focuses on learning through solving real, open-ended problems to which there are no fixed solutions. Problems can be taken from real-life news stories, generated by students themselves, and developed from realia. Students work in pairs or groups to understand the problem and then to find possible solutions to it.

Recent research reviews indicate that problem-based learning can lead to long-term learning outcomes, whereas traditional instruction leads to slightly better performance on short-term learning as measured on standardized tests. Problem-based learning is particularly effective in increasing engagement and reducing the achievement gap among participators.

Most PBL research studies have been conducted in European and American higher educational institutions and, as such, these findings may not be transferable to Ukrainian higher educational institution context without taking into consideration peculiarities of Ukrainian higher education. The main problem is how to implement interdisciplinary approach (on which PBL is based) within the Ukrainian context with its strict division between academic disciplines and university departments. Preconditions and challenges of PBL in Ukrainian higher educational institutions can be identified on three different levels: on the level of curriculum planning and structural preconditions; on the level of course planning (course assignment and other form of preparation); and on the level of implementation (role of tutors, students' performance and group dynamics). The correct implementation of PBL in Ukrainian higher educational institutions as a leading principle throughout the curriculum will lead to the integration of skills and intellectual activity of Ukrainian students and the development of self-study and the ability to think independently and solve real life problems.

\section{References:}

Albanese, M. A., \& Mitchell, S. (1993). Problem-based learning: a review of literature on its outcomes and implementation issues. Academic medicine: Journal of the Association of American Medical Colleges, 68(1), 52-81. http://dx.doi.org/10.1097/00001888-199301000-00012

Antepohl,W., Doneij, E., Forsberg, P., \& Ludvigsson, J. (2003). A follow up of medical graduates of a problem-based learning curriculum. Medical Education, 37, 155-162. http://dx.doi.org/10.1046/j.1365-2923.2003.01401.x

Barrows, H. S. (2002). Is it truly possible to have such a thing as a PBL? Distance Education, 23(1), 119-122. http://dx.doi.org/10.1080/01587910220124026

Barrows, H. S. (1996). Problem-based learning in medicine and beyond. In L. Wilkerson, \& W. H. Gijselaers (Eds.), Bringing problem-based learning to higher education: Theory and practice. New directions for teaching and learning, No. 68. (pp. 3-13). San Francisco: Jossey-Bass Inc. Publishers. http://dx.doi.org/10.1002/tl.37219966804

Beringer, Jason. (2007). Application of Problem Based Learning through Research Investigation. Journal of Geography in Higher Education, 31, 445-457. http://dx.doi.org/10.1080/03098260701514033

Busari, J.O., Scherpber, A.J.J.A., \& Boscheizen, H.P.G. (1997). Comparative study of medical education as perceived by students at three Dutch universities. Advances in Health Sciences Education, 1, 141-151. http://dx.doi.org/10.1007/bf00159278

Clayton, G., \& Pierpoint, P. (1996). Problem Based Learning: A Would-be Practitioner's Guide. University of Plymouth Business School.

Cockrell, Karen Sunday, \& Caplow, Julie A. Hughes. (2000). A Context for Learning: Collaborative Groups in the Problem-Based Learning Environment. The Reviews of Higher Education, 23, 3, 347-363. http://dx.doi.org/10.1353/rhe.2000.0008

Dmitrenko, N. (2016). Problem-based learning as a learner-centred approach: general review. Proceedings of the international conference "Modern peculiarities of the identity formation and social adaptation in conditions of liberal values crisis”, 9.02.2016-15.02.2016, London, UK.

Dolmans, D. H. J. M., \& Schmidt, H. G. (2006). What do we know about cognitive and motivational effect of small group tutorials in problem-based learning? Advances in Health Sciences Education, 11, 321-336. http://dx.doi.org/10.1007/s10459-006-9012-8 
Dolmans, D. H.J. M., De Grave, W., Wolfhagen, I. H. A. P., \& Van der Vleuten, C. P. M. (2005). Problem-based learning: Future challenges for educational practice and research. Medical Education, 39, $732-741$. http://dx.doi.org/10.1111/j.1365-2929.2005.02205.x

Ertmer, P. A., \& Newby, T. J. (2008). Behaviourism, cognitivism, constructivism: Comparing critical features from an instructional design perspective. Performance Improvement Quarterly, 6, 50-72. http://dx.doi.org/10.1111/j.1937-8327.1993.tb00605.x

Graaff, E. (2013). The Transformation Process from a Traditional Curriculum to Problem-Based and Project-Based Learning: Proceedings of 41st SEFI Conference, 16-20 September 2013, Leuven, Belgium.

Hmelo-Silver, C. E. (2004). Problem-based learning: What and how do students learn? Educational Psychology Review, 16, 235-266. http://dx.doi.org/10.1023/b:edpr.0000034022.16470.f3

Johnson, D. W., Johnson, R. T., \& Smith, K. (2006). The state of cooperative learning and professional settings. Educational Psychology Review, 19, 15-29. http://dx.doi.org/10.1007/s10648-006-9038-8

Jonassen, D. W., Hung, W. (2008). All Problems are Not Equal: Implications for Problem-Based Learning. Interdisciplinary Journal of Problem-Based Learning, 2(2). http://dx.doi.org/10.7771/1541-5015.1080

Maurer H., Neuhold Ch. (2012). PBL in European studies - Maastricht experience: The Higher Education Academy Social Science Conference "Ways of Knowing, Ways of Learning”, 28 and 29 May 2012, Liverpool Session 4 Tuesday, 29 May, 14h, Canada Suite.

Missimer, Merlina and Tamara, Connell. (2012). Pedagogical Approaches and Design Aspects To Enable Leadership for Sustainable Development. Sustainability: The Journal of Record. Vol. 5(3), 172. http://dx.doi.org/10.1089/sus.2012.9961

Ormrod, J. E. (2006). Learning and Cognitive Processes. In J. E. Ormrod (Ed.), Educational Psychology. Developing Learners. (5th ed., pp. 182-221). New Jersey: Pearson Pentice Hall.

Ormrod, J. E. (2009). Long-term memory: Storage. In J. E. Ormrod (Ed.), Human Learning (5th ed., pp. 194-231). New Jersey: Pearson Pentice Hall.

Papinczak, T., Tunny, T., \& Young, L. (2009). Conducting the symphony: a qualitative study of facilitation in problembased learning tutorials. Medical Education, 2009, Apr.; 43(4), 377-83. http://dx.doi.org/10.1111/j.13652923.2009.03293.x

Qin, Z., Johnson, D. W., \& Johnson, R. T. (1995). Cooperative Versus Competitive Efforts and Problem Solving. Review of Educational Research, 65(2), 129-143. http://dx.doi.org/10.2307/1170710

Regehr, G., \& Norman, G. R. (1996). Issues in cognitive psychology: implications for professional education. Academic medicine: Journal of the Association of American Medical Colleges, 71(9), 988-1001. http://dx.doi.org/10.1097/00001888-199609000-00015

Rudland, J. R. (2009). Learning in small groups. In J. A. Dent \& R. M. Harden (Eds.). A practical guide for medical teachers (3rd ed., pp. 80-85). Edinburgh: Churchill Livingstone Elsevier.

Schmidt, H.G., (1993). Foundations of Problem Based Learning: some explanatory notes. Maastricht: University of Limburg. Medical Education, 1993, 27 (5), 422-432. http://dx.doi.org/10.1111/j.1365-2923.1993.tb00296.x

Schmidt, H.G. (1993). Problem-based learning: an introduction. Instructional Science, 22, $247-250$. http://dx.doi.org/10.1007/bf00891778

Schmidt, H. G., Vermeulen, L., \& Van der Molen, H. T. (2006). Longterm effects of problem-based learning: a comparison of competencies acquired by graduates of a problem-based and a conventional medical school. Medical education, 40(6), 562-567. http://dx.doi.org/10.1111/j.1365-2929.2006.02483.x

Stewart, A. (2009). Instructional design. In J. A. Dent \& R. M. Harden (Eds.), A practical guide for medical teachers (3rd ed., pp. 205-210). Edinburgh: Churchill Livingstone Elsevier.

Van Boxtel, C., Van der Linden, J., \& Kanselaar, G. (2000). Deep Processing in a Collaborative Learning Environment. In H. Cowie \& G. Van der Aalsvoort (Eds.), Social interaction in learning and instruction: the meaning of discourse for the construction of knowledge (pp. 161-178). Amsterdam: Pergamon. 